\title{
Soluble uric acid increases NALP3 inflammasome and interleukin-1 $\beta$ expression in human primary renal proximal tubule epithelial cells through the Toll-like receptor 4-mediated pathway
}

\author{
JING XIAO* ${ }^{*}$ XIAO-LI ZHANG ${ }^{*}$, CHENSHENG FU, RUI HAN, WEIJUN CHEN, YIJUN LU and ZHIBIN YE \\ Department of Nephrology, Huadong Hospital Affiliated to Fudan University, Shanghai 200040, P.R. China
}

Received October 28, 2014; Accepted March 2, 2015

DOI: $10.3892 /$ ijmm.2015.2148

\begin{abstract}
Urate crystals activate innate immunity through Toll like receptor 4 (TLR4) activation, leading to the formation of the NACHT, LRR and PYD domains-containing protein 3 [NALP3; also known as NOD-like receptor family, pyrin domain containing 3 (NALP3) and cryopyrin] inflammasome, caspase- 1 activation and interleukin (IL)-1 $\beta$ expression in gout. However, whether elevated serum uric acid (UA) levels are associated with the development and progression of renal diseases without renal urate crystal deposition remains unknown. In the present study, human primary renal proximal tubule epithelial cells were incubated with soluble UA $(100 \mu \mathrm{g} / \mathrm{ml})$ with or without the TLR4 inhibitor, TAK242 $(1 \mu \mathrm{M})$. The gene expression and protein synthesis of TLR4, NALP3, caspase-1, IL-1 $\beta$ and intercellular adhesion molecule-1 (ICAM-1) were detected by real-time PCR, ELISA, western blot analysis and fluorescence-activated cell sorting (FACS), respectively. Soluble UA significantly enhanced TLR4, NALP3, caspase-1, IL-1 $\beta$ and ICAM-1 expression in the human primary renal proximal tubule epithelial cells. The TLR4 inhibitor, TAK242 effectively blocked the soluble UA-induced upregulation of TLR4, NALP3, caspase-1, IL-1 $\beta$ and ICAM-1 expression in the human primary renal proximal tubule epithelial cells. Our findings indicate that soluble UA enhances NALP3 expression, caspase- 1 activation, IL-1 $\beta$ and ICAM-1 production in renal proximal tubule epithelial cells in a TLR4-dependent manner, suggesting the activation of innate immunity in human primary renal proximal tubule epithelial cells by soluble UA.
\end{abstract}

Correspondence to: Professor Zhibin Ye, Department of Nephrology, Huadong Hospital Affiliated to Fudan University, 221 West Yan'an Road, Shanghai 200040, P.R. China

E-mail: yezhibin3@126.com

${ }^{*}$ Contributed equally

Key words: caspase-1, interleukin-1 $\beta$, nod-like receptor protein 3, human primary renal proximal tubule epithelial cells, soluble uric acid, Toll like receptor 4

\section{Introduction}

Hyperuricemia is a consistent and independent risk factor for hypertension, metabolic syndrome, fatty liver, diabetes and kidney diseases (1-3). Tubulointerstitial inflammation and injury are commonly detected in hyperuricemia-induced chronic renal injury, with increased macrophage and $\mathrm{T}$ cell infiltration observed in the tubulointerstitium of the kidneys $(4,5)$. As some patients with hyperuricemia present with urate crystal deposition in the tubules and interstitium, it was previously assumed that hyperuricemia causes tubular injury through the precipitation of urate in the form of crystals in the kidneys, in a manner similar to which it causes gout. In gout, urate crystals cause inflammation by stimulating leukocytes to produce the pro-inflammatory cytokine, interleukin-1 $\beta$ (IL-1 $\beta$ ). IL-1 production occurs when the urate particles are ingested by phagocytes through the Toll like receptor 4 (TLR4) activation pathway, which facilitates the formation of the NACHT, LRR and PYD domains-containing protein 3 [NALP3; also known as NOD-like receptor family, pyrin domain containing 3 (NALP3) and cryopyrin] inflammasome, thus promoting pro-caspase-1 activation, further activating caspase-1; activated caspase- 1 then cleaves pro-IL-1 $\beta$ into its active form IL-1 $\beta$ and, thus, initiates downstream inflammatory processes $(6,7)$. Accumulating evidence has demonstrated that urate crystal-induced inflammation is a paradigm of innate immunity. Innate immunity-related components, including TLR4, NALP3, ASC, caspase-1 and IL-1 $\beta$ are essential in the development of gouty inflammation (8). However, recent findings suggest that the presence of elevated soluble serum uric acid (UA) levels represent the presence of low-grade systemic inflammation even in the absence of gout (9). A recent ultrasound study also suggested that ultrasonographic changes suggestive of gouty arthritis in joints and tendons may occur in patients with asymptomatic hyperuricaemia who have never had an episode of gout (10). Moreover, as urate crystal is as less likely to be deposited in the kidneys as in the joints, these recent findings suggest that, not only urate crystals, but also soluble UA may account for the injury in patients with hyperuricemia. However, whether soluble UA can also lead to the TLR4-mediated activation of innate immunity remains unknown.

Soluble UA may have direct pro-inflammatory effects as shown by previous studies, including stimulating the production of C-reactive protein (CRP) and monocyte chemotactic 
protein-1 (MCP-1) in vascular cells through the activation of nuclear factor- $\kappa \mathrm{B}(\mathrm{NF}-\kappa \mathrm{B})$ and mitogen-activated protein kinase (MAPK) $(11,12)$, inducing endothelial dysfunction with mitochondrial alterations and decreased intracellular adenosine triphosphate (ATP) concentrations (13), exerting pro-oxidative effects mediated in part by the activation of the lactaldehyde reductase (NADPH) oxidase system and stimulating mitochondrial oxidative stress in vascular cells or adipocytes (14). In the kidneys, observational studies have also observed renal injuries induced by soluble UA without urate crystal formation induced by inflammation (15-18). In clinical observations, not only hyperuricemia, but also a higher normal level of UA has been shown to increase the risk of the early progression of renal function loss in patients with type 1 diabetes (19). In hyperuricemic rats, renal disease has been shown to progress rapidly without the presence of urate crystals in the kidneys (18). In vitro findings have also suggested that soluble UA actively participates in pro-inflammatory processes in vascular smooth muscle cells and mesangial cells $(11,15,16)$. However, these studies failed to illustrate the mechanisms of soluble UA-induced renal injury and did not investigate the upstream events of the proinflammatory effects of soluble UA.

As kidney diseases, including some metabolic renal injuries, often manifest with renal immune dysregulation (20), it is possible that soluble UA may directly induce renal tubular injury without urate crystal deposition. More importantly, the TLR4-mediated activation of innate immunity may be involved as an upstream event for the pro-inflammatory effects of soluble UA. Therefore, we hypothesized that soluble UA may cause innate immune injury through the TLR4-dependent pathway, and may thus promote the formation of the NALP3 inflammasome, the activation of caspase-1, the expression of IL-1 $\beta$ and the overproduction of downstream inflammatory cytokines. In order to verify this hypothesis, in the present study, we incubated human primary renal proximal tubule epithelial cells (PTECs) with soluble UA and then measured the expression levels of TLR4, the NALP3 inflammasome, caspase-1 and IL-1 $\beta$, as well as those of the inflammatory marker, intercellular adhesion molecule-1 (ICAM-1). We also used the TLR4-specific inhibitor, TAK242, to block the effects of TLR4 so as to determine whether the effects of soluble UA on PTECs are TLR4-dependent.

\section{Materials and methods}

Reagents. Human primary renal PTECs and their culture medium were purchased from ScienCell (San Diego, CA, USA). UA was purchased from Sigma (St. Louis, MO, USA). The TLR4 inhibitor, TAK242, was purchased from Chembest Research Laboratories Ltd. (Shanghai, China). The MTT assay kit was from Amresco (Solon, OH, USA). Reagents for real-time PCR were purchased from Takara (Kyoto, Japan). Enzyme immunoassay kits for the detection of IL-1 $\beta$ were purchased from eBioscience (San Diego, CA, USA). Anti-TLR4 (Cat. no. ab22048) and anti-CIAS1/NALP3 (Cat. no. ab16097) antibodies were from Abcam (Cambridge, UK). Anti-caspase-1 (Cat. no. sc-515) and anti-ICAM-1 (Cat. no. sc-8439) antibodies were from Santa Cruz Biotechnology (Dallas, TX, USA). Anti-mouse (Cat. no. A0216) and anti-rabbit (Cat. no. A0208) secondary antibodies were from SinoBios (Shanghai, China).
Cell culture. Human primary renal PTECs were cultured in epithelial cell medium, which contains $500 \mathrm{ml}$ of basal medium, $50 \mathrm{ml}$ of fetal bovine serum, $5 \mathrm{ml}$ of epithelial cell growth supplement and $5 \mathrm{ml}$ of penicillin/streptomycin solution. The cells were incubated at $37^{\circ} \mathrm{C}$ in $5 \% \mathrm{CO}_{2}$ and $95 \%$ air. In all the experiments, there was a 'growth arrest' period of $24 \mathrm{~h}$ in serum-free medium prior to stimulation.

Preparation of soluble UA. UA was dissolved in $1 \mathrm{M} \mathrm{NaOH}$ at a concentration of $50 \mathrm{mg} / \mathrm{ml}$ as previously described (21). The solution was examined free of mycoplasma and filtered $(22 \mu \mathrm{m}$ pore size) before use. Crystals were not detectable (polarizing microscopy), nor did they develop during cell incubation.

Viability of PTECs under increasing concentrations of soluble UA. To examine cell viability following treatment with various concentrations of soluble UA, the growth-arrested human primary renal PTECs were seeded in 96-well plates $\left(0.25 \times 10^{5}\right.$ cells/well $)$ and exposed to soluble UA $(0-800 \mu \mathrm{g} / \mathrm{ml})$ for 24,48 and $72 \mathrm{~h}$, respectively. The effects of treatment with TAK242 on cell viability $(0.25-2 \mu \mathrm{M})$ were also examined. Subsequently, the cytotoxic effects of these stimulations on the human primary renal PTECs were examined by MTT assay. Briefly, $20 \mu \mathrm{l}$ MTT solution were added to each well, and the cells were incubated at $37^{\circ} \mathrm{C}$ in $5 \% \mathrm{CO}_{2}$ and $95 \%$ air for $4 \mathrm{~h}$. The reaction was terminated by the addition of $150 \mu 1 \mathrm{DMSO}$, and the absorbance was measured at $570 \mathrm{~nm}$ by an ELISA reader. All results were expressed as percentage changes in absorbance compared with those of the medium control (defined as human primary renal PTECs incubated with plain culture medium).

Total RNA extraction and real-time PCR for the quantification of TLR4 and ICAM-1 gene expression. The growth-arrested human primary renal PTECs were incubated $100 \mu \mathrm{g} / \mathrm{ml}$ of soluble UA for $4 \mathrm{~h}$. Total cellular RNA was extracted using the NucleoSpin RNA II total RNA extraction kit. The quality of the extracted RNA was monitored by formaldehyde agarose gel electrophoresis. Aliquots of each RNA extraction were reverse transcribed simultaneously into cDNA using the OneStep RT-PCR kit (Takara, Tokyo, Japan) according to the manufacturer's instructions. Each real-time PCR reaction was performed in a total volume of $25 \mu \mathrm{l}$ in duplicate using the $\mathrm{SYBR}^{\circledR}$ Premix Ex $\mathrm{Taq}^{\mathrm{TM}}$ kit (Takara, Kyoto, Japan) and the Fast Real-Time PCR system 7500 (Applied Biosystems Inc., Foster City, CA, USA). Primers and probe sets for human TLR4 and ICAM-1 were designed from known sequences in GenBank and the primer sequences are listed in Table I. GAPDH was used as an endogenous control to normalize the amount of cDNA added to each reaction $\left(\Delta \mathrm{C}_{\mathrm{T}}\right)$, and the mean $\Delta \mathrm{C}_{\mathrm{T}}$ value of the control samples was used as the calibrator to calculate the $\Delta \Delta \mathrm{C}_{\mathrm{T}}$ value. The quantification of each transcript was calculated using the comparative $\mathrm{C}_{\mathrm{T}}$ method. In this method, the relative quantity of the target mRNA, normalized to the endogenous control and relative to the calibrator, is equal to $2^{-\Delta \Delta \mathrm{CT}}$.

ELISA of IL-1 $\beta$ protein synthesis in cell culture supernatants. The growth-arrested human primary renal PTECs were incubated with $100 \mu \mathrm{g} / \mathrm{ml}$ soluble UA for $48 \mathrm{~h}$. Cell culture supernatants were collected and stored at $-70^{\circ} \mathrm{C}$ until use in the protein assay. The protein levels of IL-1 $\beta$ in the culture superna- 
Table I. Primer sequences and size of PCR products.

\begin{tabular}{llcc}
\hline Genes & \multicolumn{1}{c}{$5^{\prime} \rightarrow 3^{\prime}$ sequences of PCR primers } & Size of products (bp) & Accession number \\
\hline$T L R 4-f$ & ACA AGT GAT GTT TGA TGG ACC TCT & 283 & U88880 \\
$T L R 4-r$ & TCT TGA ATG TTC TGT TTC TGA GGA G & 189 & NM_000201 \\
$I C A M-1-f$ & TTG AAC CCC ACA GTC ACC TAT & 118 & X01677 \\
$I C A M-1-r$ & CCT CTG GCT TCG TCA GAA TCA & \\
$G A P D H-f$ & ATG GGG AAG GTG AAG GTC G & \\
$G A P D H-r$ & GGG GTC ATT GAT GGC AAC AAT A & \\
\hline
\end{tabular}
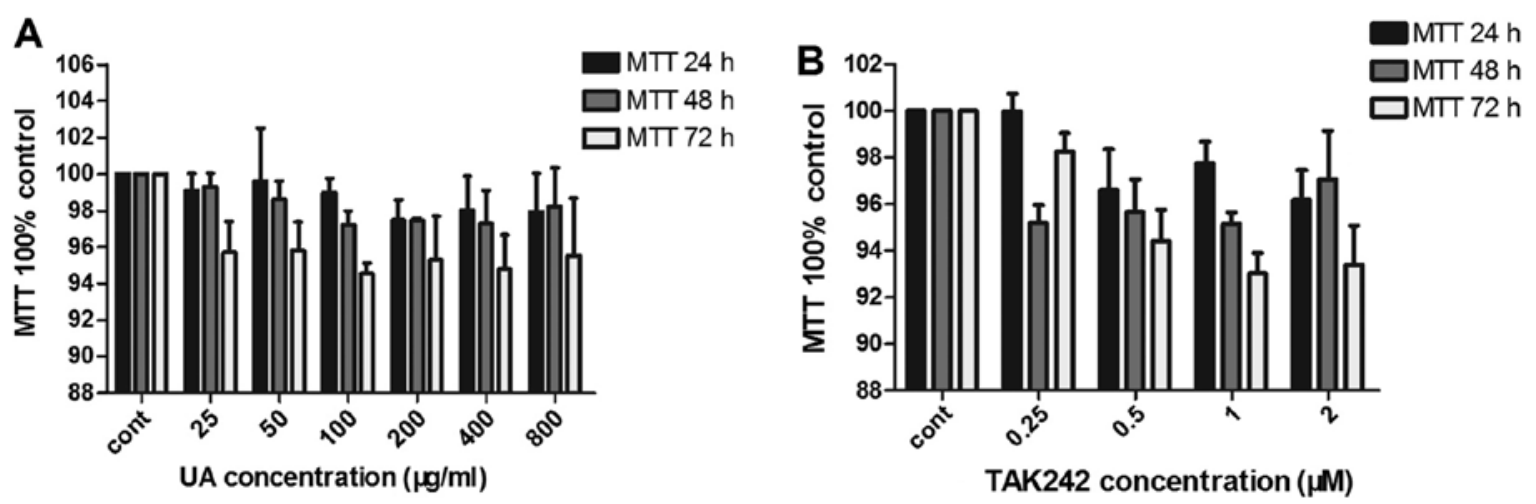

Figure 1. Viability of cultured human primary renal proximal tubule epithelial cells (PTECs) following incubation with soluble uric acid (UA). Human primary renal PTECs were cultured with different concentrations of soluble UA $(0-800 \mu \mathrm{g} / \mathrm{ml})$ and the Toll like receptor 4 (TLR4) inhibitor, TAK242 (0-2 $\mu \mathrm{M})$, for 24,48 and $72 \mathrm{~h}$. MTT assay revealed that (A) soluble UA from 0 to $800 \mu \mathrm{g} / \mathrm{ml}$ and (B) TAK242 from 0.25 to $2 \mu \mathrm{M}$ did not affect the cell viability at all the time points examined. Results are expressed as percentage changes in absorbance relative to those of the human primary renal PTECs incubated in plain medium alone. All results represent the means \pm SD obtained from 3 independent experiments.

tants were determined by commercial assay kits. The procedures were carried out according to the manufacturer's instructions.

Western blot analysis for the protein expression of TLR4, the NALP3 inflammasome and caspase-1. After harvesting the cell culture supernatant as described above, the remaining cells were lysed with lysis buffer containing protease inhibitor cocktails (Sigma). Ten micrograms of total protein extracted from $10^{6}$ cells were electrophoresed through a $12 \%$ SDS-PAGE gel before being transferred onto polyvinylidene difluoride (PVDF) membranes. After blocking for $1 \mathrm{~h}$ at room temperature in blocking buffer [5\% bovine serum albumin in Tris-buffered saline (TBS) with $0.05 \%$ Tween-20 (TBST)], the membranes were incubated overnight with mouse anti-TLR4 (3:500), mouse anti-CIAS1/NALP3 (1:1,000), rabbit anti-caspase-1 p10 (1:500) and rabbit anti-GAPDH $(1: 10,000)$ in TBST. The membranes were washed and incubated for $1 \mathrm{~h}$ at room temperature with a peroxidase-labeled goat anti-rabbit (Cat. no. A0208) or goat anti-mouse (Cat. no. A0216) immunoglobulin (SinoBios). After further washing, the membranes were detected by ECL chemiluminescence (Amersham Pharmacia Biotech, Arlington Heights, IL, USA).

ICAM-1 detection by fluorescence-activated cell sorting (FACS) analysis. After an incubation of $48 \mathrm{~h}$ with $100 \mu \mathrm{g} / \mathrm{ml}$ of soluble UA, the human primary renal PETCs were detached with $0.25 \%$ trypsin in $1 \mathrm{mM}$ ethylenediamine tetraacetic acid4Na, washed twice with PBS buffer, $\mathrm{pH} 7.2$, and then incubated with fluorescein isothiocyanate-conjugated anti-human ICAM-1 (1:50; Santa Cruz Biotechnology) for $1 \mathrm{~h}$ in an icebath. The expression of ICAM-1 was detected using a FACScan (BD FACS Caljbur; BD Bioscience, San Jose, CA, USA). Data were compared as the geometric mean (GMean) values of the fluorescence intensity of the ICAM-1-positive cells. The same experiment was repeated 3 times.

Statistical analysis. All data are expressed as the means \pm SD unless otherwise specified. Statistical analysis was performed using SPSS v.19.0 for Windows (SPSS, Inc., Chicago, IL, USA). Intergroup differences for continuous variables were assessed by multivariate ANOVA. A value of $\mathrm{P}<0.05$ was considered to indicate a statistically significant difference.

\section{Results}

Viability of human primary renal PTECs and $p H$ value of the medium following incubation with soluble UA and TAK242. The viability of the human primary renal PTECs cultured with serial dilutions of soluble UA and TAK242 (TLR4 inhibitor) for 24, 48 and $72 \mathrm{~h}$ was examined by MTT assay. The results revealed that soluble UA (Fig. 1A) from 0 to $800 \mu \mathrm{g} / \mathrm{ml}$ and TAK242 (Fig. 1B) from 0.25 to $2 \mu \mathrm{M}$ did not affect the cell viability at all the time points examined $(\mathrm{P}>0.05)$. The $\mathrm{pH}$ values of the human primary renal PTECs in the culture medium following the addition of soluble UA were examined using a pH meter (Merck, Darmstadt, Germany). The $\mathrm{pH}$ values were all within the range of 7.1 to 7.4. 


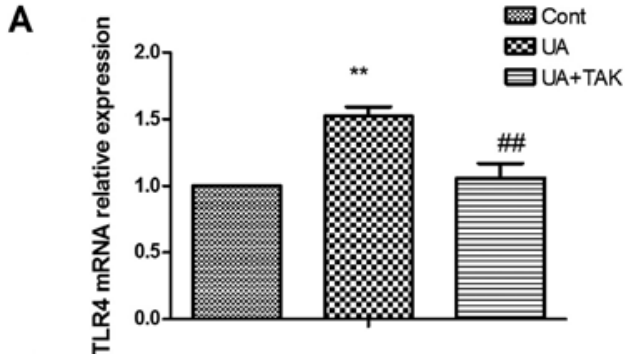

B

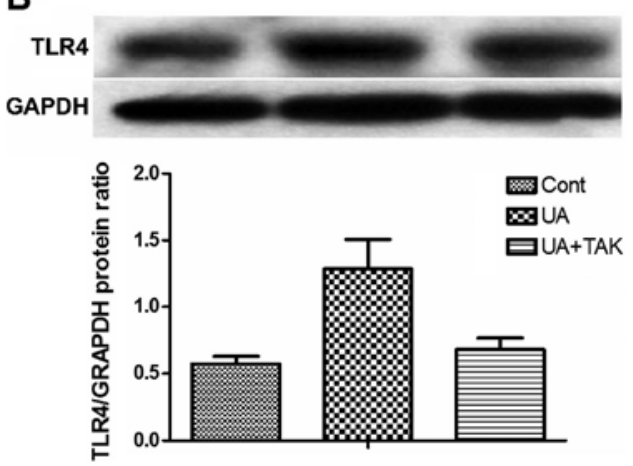

Figure 2. Gene and protein expression of Toll like receptor 4 (TLR4) in human primary renal proximal tubule epithelial cells (PTECs) cultured with soluble uric acid (UA). Human primary renal PTECs were incubated with soluble $\mathrm{UA}(100 \mu \mathrm{g} / \mathrm{ml})$ for $4 \mathrm{~h}$ (gene expression) or for $48 \mathrm{~h}$ (protein expression). The TLR4-specific inhibitor, TAK242 $(1 \mu \mathrm{M})$, was added to the human primary renal PTECs $1 \mathrm{~h}$ prior to stimulation with soluble UA. The results from real-time PCR and western blot analysis revealed that soluble UA increased the (A) mRNA expression and (B) protein synthesis of TLR4. TAK242 significantly blocked the $100 \mu \mathrm{g} / \mathrm{ml}$ soluble UA-induced incresae in (A) TLR4 mRNA expression and (B) TLR4 protein synthesis. All results represent the means \pm SD obtained from 3 independent experiments. ${ }^{* *} \mathrm{P}<0.01$ vs. human primary renal PTECs cultured in plain medium; ${ }^{\# \#} \mathrm{P}<0.01 \mathrm{vs}$. human primary renal PTECs cultured with the same concentration of soluble UA but withou TAK242. Representative images of the corresponding protein bands are shown at the top of each bar in (B).

Soluble UA increases TLR4 expression in human primary renal PTECs. To determine whether the innate immunity of the human primary renal PTECs by soluble UA was activated, the expression of TLR4, a typical membrane receptor for innate immunity (22), was examined following treatment with $100 \mu \mathrm{g} / \mathrm{ml}$ soluble UA for $4 \mathrm{~h}$ (gene expression) or $48 \mathrm{~h}$ (protein expression) with or without $1 \mathrm{~h}$ pre-incubation with the TLR4 inhibitor, TAK242 $(1 \mu \mathrm{M})$. The results from real-time PCR and western blot analysis revealed that treatment with soluble UA significantly upregulated the TLR4 gene (Fig. 2A; $\mathrm{P}<0.01$ ) and protein (Fig. $2 \mathrm{~B} ; \mathrm{P}<0.01$ ) expression in the human primary renal PTECs. TAK242 reversed this upregulation of soluble UA-induced TLR4 gene (Fig. 2A; $\mathrm{P}<0.01$ ) and protein expression (Fig. 2B; $\mathrm{P}<0.01$ ) in the human primary renal PTECs.

Induction of TLR4-dependent NALP3 expression by soluble $U A$ in human primary renal PTECs. The formation of the NALP3 inflammasome is initiated upon TLR4 activation (22). Thus, in order to examine the soluble UA-induced activation of innate immunity following tubular damage, NALP3 expression was measured by western blot analysis after the human primary renal PTECs were incubated with $100 \mu \mathrm{g} / \mathrm{ml}$ soluble UA for $48 \mathrm{~h}$. TAK242 $(1 \mu \mathrm{M})$ was added to the human primary renal PTECs $1 \mathrm{~h}$ prior to stimulation with soluble UA. Soluble UA significantly enhanced NALP3 protein expression in the human primary renal PTECs (Fig. 3A; P<0.01). TAK242 reversed this soluble UA-induced increase in NALP3 protein expression in the human primary renal PTECs (Fig. 3A; $\mathrm{P}<0.01$ ).

TLR4-dependent caspase-1 activation by soluble UA in human primary renal PTECs. Caspase-1 is the activated form processed from pro-caspase-1 by the downstream process of the NALP3 inflammasome (23). In order to determine the function of the NALP3 inflammasome, caspase-1 activation in the human primary renal PTECs was examined by western blot analysis following stimulation with $100 \mu \mathrm{g} / \mathrm{ml}$ soluble UA for $4 \mathrm{~h}$. To determine whether the activation of TLR4 is specific for soluble UA-induced caspase-1 activation, the TLR4-specific inhibitor, TAK242 $(1 \mu \mathrm{M})$, was added to the human primary renal PTECs $1 \mathrm{~h}$ prior to stimulation with soluble UA. Soluble UA significantly promoted caspase-1 activation in the human primary renal PTECs (Fig. 3B; $\mathrm{P}<0.05$ ), whereas TAK242 reversed this soluble UA-induced activation of caspase-1 in the human primary renal PTECs (Fig. 3B; $\mathrm{P}<0.05$ ).

Induction of TLR4-dependent IL-1 $\beta$ protein synthesis by soluble UA in human primary renal PTECs. IL-1 $\beta$ can be cleaved from pro-IL-1 $\beta$ by caspase-1 (24). In order to determine the effects of activated caspase-1, IL-1 $\beta$ protein expression in the human primary renal PTECs was examined by ELISA following stimulation with $100 \mu \mathrm{g} / \mathrm{ml}$ UA for $48 \mathrm{~h}$. To determine whether the activation of TLR4 is specific for soluble UA-induced IL- $1 \beta$ protein expression, the TLR4specific inhibitor, TAK242 $(1 \mu \mathrm{M})$, was added to the human primary renal PTECs $1 \mathrm{~h}$ prior to stimulation with soluble UA. Soluble UA significantly upregulated IL- $1 \beta$ protein expression in the human primary renal PTECs (Fig. 3C; P<0.01). TAK242 reversed this soluble UA-induced increase in IL-1 $\beta$ protein expression (Fig. 3C; $\mathrm{P}<0.01$ ).

Induction of TLR4-dependent ICAM-1 expression by soluble UA in human primary renal PTECs. ICAM-1 is the downstream cytokine of IL- $1 \beta$ production which facilitates the adhesion of monocytes/macrophages to injured tubulointerstitial tissue (25). In order to determine the downstream effect of IL-1 $\beta$, the gene and protein expression levels of ICAM-1 in the human primary renal PTECs were examined by real-time PCR and FACS analysis following stimulation with $100 \mu \mathrm{g} / \mathrm{ml}$ soluble UA for $4 \mathrm{~h}$ (gene expression) or $48 \mathrm{~h}$ (protein expression), respectively. To determine whether the activation of TLR4 is specific for soluble UA-induced ICAM-1 expression, the TLR4-specific inhibitor, TAK242 $(1 \mu \mathrm{M})$, was added to the human primary renal PTECs $1 \mathrm{~h}$ prior to stimulation with soluble UA. As indicated in Fig. 4, soluble UA significantly upregulated ICAM-1 gene (Fig. $4 \mathrm{~A} ; \mathrm{P}<0.05$ ) and protein expression on the cell surface (Fig. 4B; P $<0.01$ ). TAK242 reversed this soluble UA-induced increase in ICAM-1 gene and protein expression on the cell surface (Fig. 4; $\mathrm{P}<0.05$ ).

\section{Discussion}

Serum UA levels are elevated in chronic kidney disease and closely correlate with the progression of renal disease (26). However, whether soluble UA actively participates in renal 
A

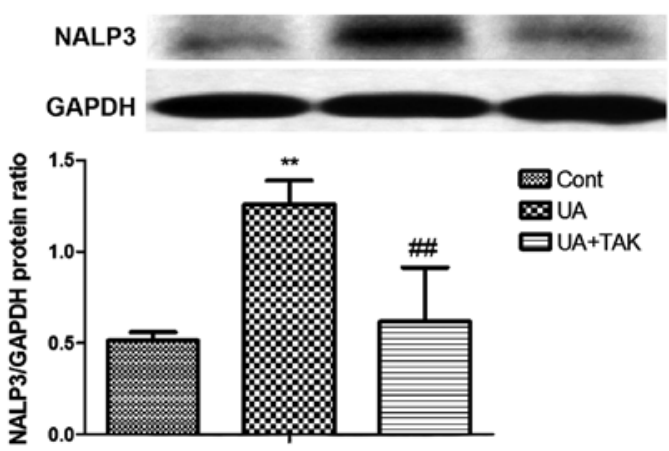

B

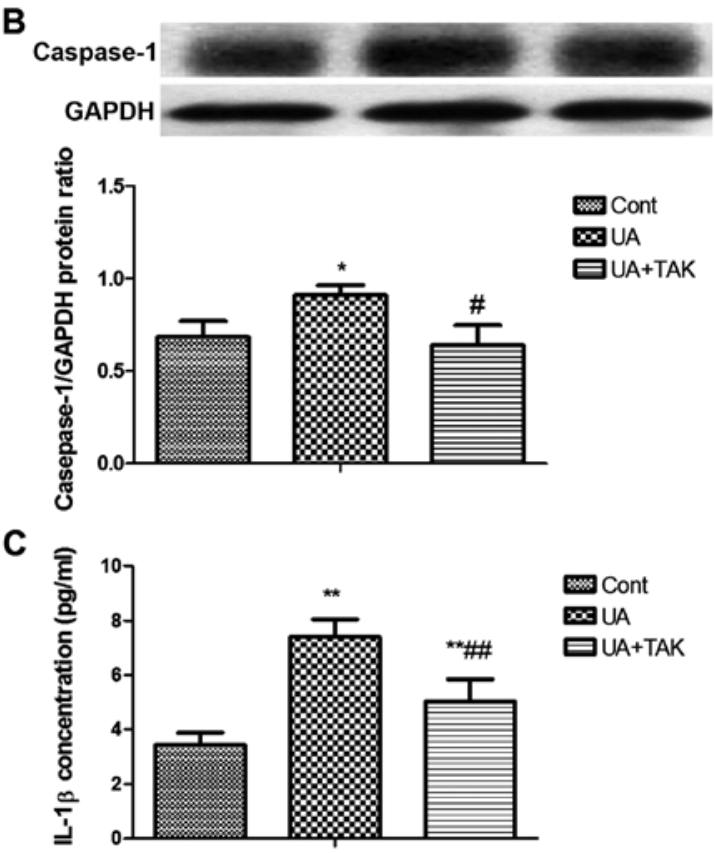

Figure 3. Toll like receptor 4 (TLR4)-dependent protein expression of NODlike receptor family, pyrin domain containing 3 (NALP3), caspase-1 and interleukin-1 $\beta$ (IL-1 $\beta$ ) in human primary renal proximal tubule epithelial cells (PTECs) cultured with soluble uric acid (UA). Human primary renal PTECs were incubated with soluble UA $(100 \mu \mathrm{g} / \mathrm{ml})$ for $48 \mathrm{~h}$ (for NALP3 and IL-1 $\beta$ ) or for $4 \mathrm{~h}$ (for caspase-1). The TLR4-specific inhibitor, TAK242 $(1 \mu \mathrm{M})$, was added to the human primary renal PTECs $1 \mathrm{~h}$ prior to stimulation with soluble UA. The NALP3 inflammasome and caspase-1 protein expression were examined by western blot analysis and IL-1 $\beta$ protein synthesis was examined by ELISA. UA significantly enhanced the protein expression of (A) NALP3, (B) caspase-1 and (C) IL-1 $\beta$ protein synthesis. TAK242 significantly blocked $100 \mu \mathrm{g} / \mathrm{ml}$ soluble UA induced upregulation of (A) NALP3, (B) caspase-1 and (C) IL-1 $1 \beta$ protein synthesis. All results represent the means \pm SD obtained from 3 independent experiments. ${ }^{*} \mathrm{P}<0.05,{ }^{* * *} \mathrm{P}<0.01$ vs. human primary renal PTECs cultured in plain medium; ${ }^{\# \#} \mathrm{P}<0.01$ vs. human primary renal PTECs cultured with the same concentration of soluble UA but without TAK242. Representative images of the corresponding protein bands are shown at the top of each bar.

injury is incompletely understood, which substantially limits our clinical understanding of this recently revisited disease at the entity. In the present study, we found that soluble UA significantly induced the upregulation of pro-inflammatory cytokine ICAM-1 expression with TLR4-NALP3-caspase-1IL-1 $\beta$ signaling pathway activation in cultured human primary renal PTECs, indicating that soluble UA may participate in the development and progression of renal disease through the TLR4-mediated activation of innate immunity.

Our results are indicative as we selected human primary renal PTECs, which share most of the properties of the human
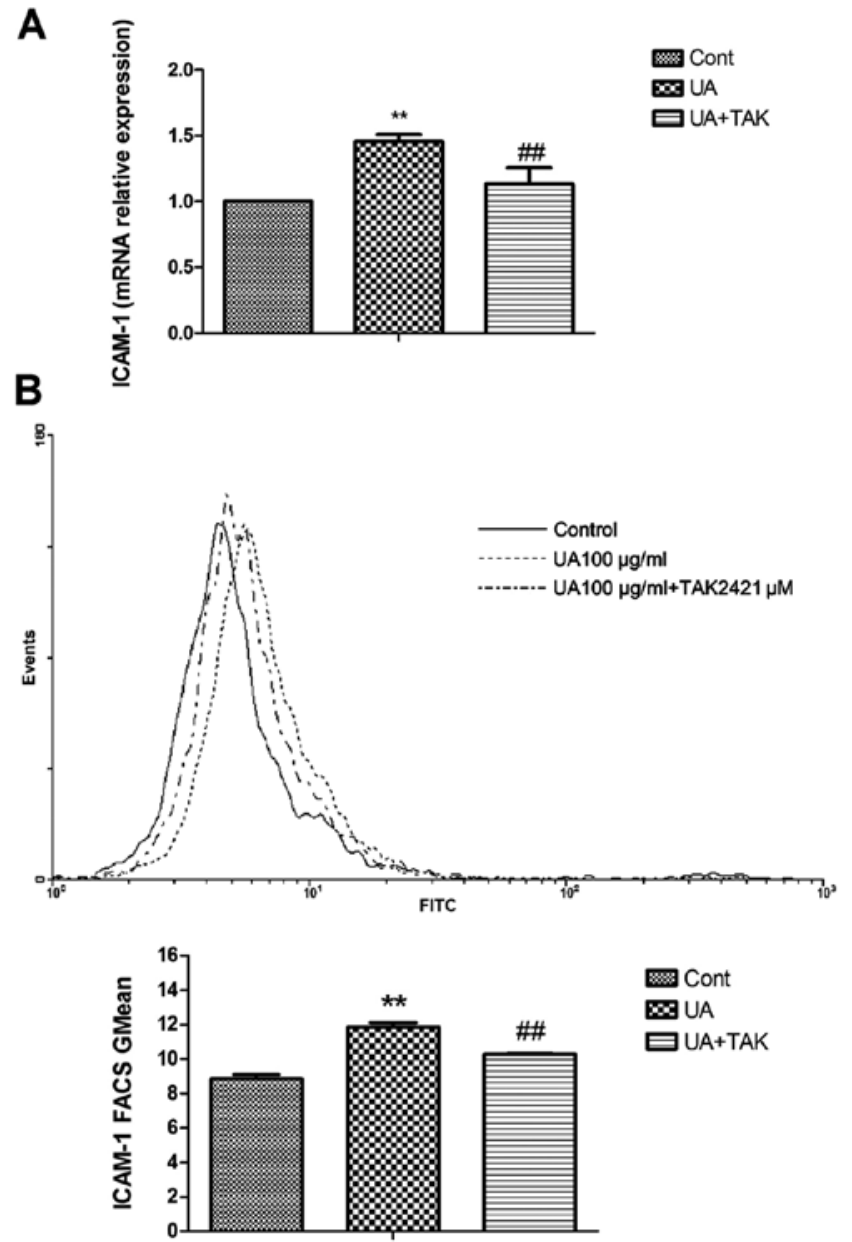

Figure 4. Induction of Toll like receptor 4 (TLR4)-dependent gene and protein expression of intercellular adhesion molecule-1 (ICAM-1) in human primary renal proximal tubule epithelial cells (PTECs) cultured with soluble uric acid (UA). Human primary renal PTECs were incubated with soluble UA $(100 \mu \mathrm{g} /$ $\mathrm{ml}$ ) for $4 \mathrm{~h}$ for the analysis of the mRNA expression and $48 \mathrm{~h}$ for the analysis of the protein expression of ICAM-1 and soluble ICAM-1. The TLR4-specific inhibitor, TAK242 $(1 \mu \mathrm{M})$, was added to the human primary renal PTECs $1 \mathrm{~h}$ prior to stimulation with soluble UA. ICAM-1 gene expression was examined by real-time PCR. ICAM-1 protein expression was examined by FACS. Soluble UA significantly enhanced ICAM-1 (A) gene and (B) protein expression. TAK242 significantly blocked the soluble UA-induced upregulation of ICAM-1 gene and protein expression in the human primary renal PTECs. All results represent the means \pm SD obtained from 3 independent experiments. ${ }^{*} \mathrm{P}<0.05,{ }^{* * *} \mathrm{P}<0.01$ vs. human primary renal PTECs cultured in plain medium; ${ }^{\# \#} \mathrm{P}<0.01$ vs.human primary renal PTECs cultured with the same concentration of soluble UA but without TAK242.

situation compared with other immortalized human renal tubular cells or primary cells from other species. Studies on the effects of UA on tubular cells have mainly used rat (4,27-29) and rabbit (30) tubular cells or the human proximal tubule epithelial cell line, HK-2 $(29,31)$. In the studies on rat renal proximal tubular cells, UA was shown to possess pro-inflammatory and pro-fibrotic properties $(4,27,28)$. One study in 2007 found that UA inhibited rat renal proximal tubule cell proliferation through at least two signaling pathways involving protein kinase C, MAPK, cytosolic phospholipase A2 and NF-kB (30). Later, UA was shown to induce cell apoptosis by regulating apoptotic proteins (29) in the human renal tubular cell line, HK-2, to induce epithelial-to-mesenchymal transition (27) and to increase fibronectin synthesis (28) in rat renal 


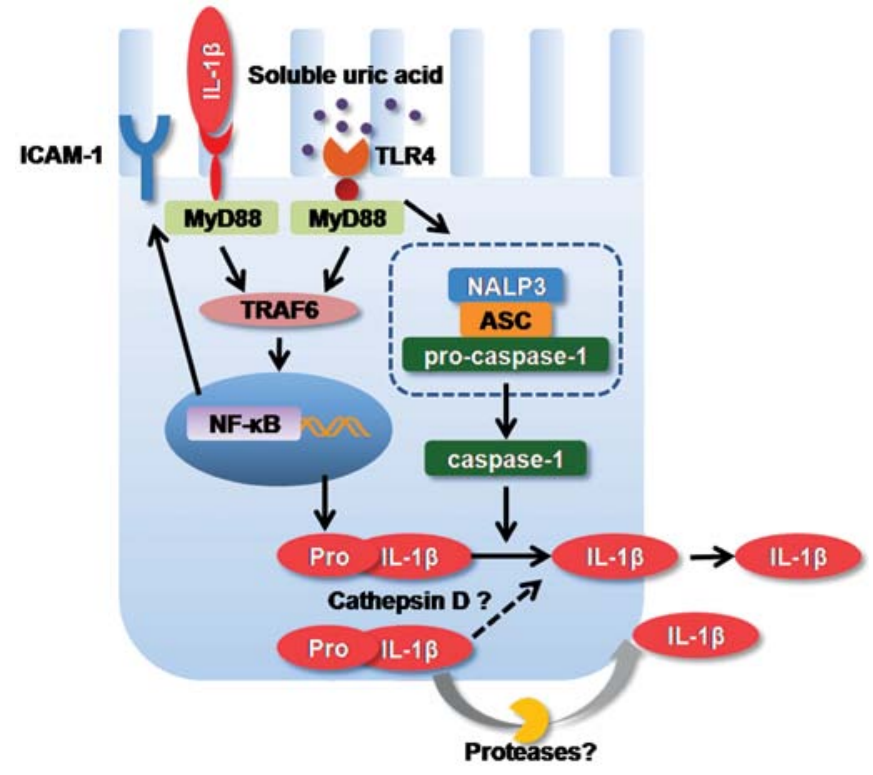

Figure 5. Proposed scheme of the Toll like receptor 4 (TLR4)-mediated cellular activation of innate immunity following stimulation with soluble uric acid. Soluble uric acid (UA) interacts with TLR4, activating the classical TLR4/MyD88/TRAF6/NF-кB signaling pathway, increasing pro-interleukin (IL) $-\beta$ production [as proven by other studies $(51,52)$ ] and initiating the formation of the NOD-like receptor family, pyrin domain containing 3 (NALP3) inflammasome by recruiting the adapter protein, ASC, and pro-caspase-1 to the complex. Recruitment to the inflammasome triggers caspase-1 autoprocessing and the generation of the active p10/20 heterodimeric enzyme. Active caspase- 1 cleaves pro-IL- $1 \beta$ into its active form, IL- $1 \beta$. IL- $1 \beta$ binds its receptor, IL-1R, and acts through the MyD88/TRAF6/NF- $\kappa \mathrm{B}$ signaling pathway to increase intercellular adhesion molecule-1 (ICAM-1) expression. Cathepsin D or other proteases released from human primary renal proximal tubule epithelial cells (PTECs) may help to cleave active IL-1 $\beta$. Question marks and dash lines indicate suspected links.

epithelial cells. These studies have elegantly demonstrated the downstream effects of UA; however, they failed to provide the upstream information for the mechanisms through which UA triggers these pro-inflammatory cascades. In the present study, we observed the upregulation of ICAM-1, an important proinflammatory cytokine mediating the interaction of resident renal cells to immune cells (32). The soluble UA-induced overepxression of ICAM-1 was dependent on TLR4 activation, as the TLR4 inhibitor reversed this soluble UA-induced upregulation of ICAM-1, suggesting that TLR4-mediated immunity is UA-dependent and may be capable of leading to the activatio of other pro-inflammatory cascades.

Innate immunity has recently been found to be great interest even in several metabolic diseases (20). It is closely associated with disease initiation and progression; the participation of the innate and the adaptive immune response in mechanisms that contribute to inflammation in cardiovascular disease has been reported in atherosclerosis and hypertension (33). The involvement of immune dysregulation in cardiac, vascular and renal changes in hypertension has been demonstrated in experimental models (34). Renal epithelial cells are also immune privileged and are surrounded by a dense network of immune cells, which provides an environment for the communication of tubular cells with immune cells. In fact, renal epithelial cells share many phenotypic and functional characteristics with mononuclear phagocytes, such as the secretion of chemokines in response to direct stimulation with TLR ligands (35) and the expression of major histocompatibility complex (MHC) I and II, as well as co-stimulatory molecules. There are even data suggesting that proximal tubules can present antigen to T cells (36).

The urate crystal form of UA, monosodium urate (MSU) crystals, has been suggested to be a so-called 'danger signal' that alerts the immune system to cell injury and helps to trigger both innate and adaptive immune responses (7). The triggered immune responses initiate the production of pro-inflammatory cytokines and then facilitate the communication between immune cells and local tissue cells. It is only found in immune cells and soluble UA directly activates T cells without antigen presentation (21). In the present study, we provide further evidence in that soluble UA modulates the innate immune injury with the formation of the TLR4-dependent NALP3 inflammasome, resulting in caspase- 1 activation, IL-1 $\beta$ and ICAM- 1 production in human primary renal PTECs. Innate immunity has been shown to trigger inflammation in a number of diseases (37) and, thus, our findings suggest that the many pro-inflammatory effects of UA may be initiated by the activation of innate immunity through TLR4. Targeting the innate immunity pathway may provide an alternative for the treatment of diseases with inflammation.

TLRs are typical membrane receptors for innate immunity and are the first line of defense during the innate immune response (38). Studies have documented the TLR4-mediated pro-inflammatory effects in podocytes (39), oxidative stress in mesangial cells $(40)$ and renal tubular damage $(41,42)$ in proximal tubular cells under the stimulation of high glucose, lipopolysaccharide and lipids. TLR4 has also been recognized as a receptor for UA and plays a significant role in amplifying inflammatory effects (6). In peripheral blood from patients with acute gout arthritis, the NF- $\kappa \mathrm{B}$ level and IL- $1 \beta$ production were markedly reduced after TLR4 blockade with anti-TLR4 antibody (43), suggesting the key role of TLR4 in gout. TLR4 signaling, including the adaptor molecule myeloid differentiation factor 88 (MyD88) and the inflammasome complex, actively participates in mediating experimental tubule-interstitial nephritis (44). In experimental renal transplantation, local TLR4 activation by endogenous ligands may be a pathological link from unspecific primary damage to subsequent chemokine release, and the infiltration and activation of immune cells, leading to the deterioration of renal function and the induction of renal fibrosis, in which UA may play an important role (45). However, to the best of our knowledge, whether TLR4 is an alternative pathway for UA activation in renal tubular cells and whether it is a link between metabolic injury to subsequent inflammatory cytokine release has not been previously examined. In the present study, TLR4 expression was elevated by soluble UA and the TLR4 inhibitor, TAK242, significantly blocked the downstream NALP3 inflammasome, caspase- 1 activation, IL-1 $\beta$ and ICAM- 1 synthesis induced by soluble UA, indicating the TLR4-dependent effects of soluble UA. The inflammatory cytokine, ICAM-1, was also blocked by the TLR4 inhibitor, suggesting that TLR4 may be such a bridge to link metabolic damage to inflammatory injury.

Extensive examination of the entering of UA into tubular cells has revealed the presence of urate transporters on both sides of tubular cells which mediate the absorption and excretion of UA (46), as well as many of the detrimental effects of 
UA $(4,27)$. However, in a previous study, the inhibitor of urate transporter could not completely block the pro-inflammatory effects of UA (28), suggesting the activation of other systems which may also account for the injury. The innate immune response has also been demonstrated to participate in recognition, uptake and the responses of cells to MSU crystals in immune cells. Recognition of the naked MSU crystal by TLR2 and TLR4 has been shown to promote the ingestion of naked MSU crystal by phagocytes $(6,47)$. As the uptake of urate by urate transporters has not been examined for its association with innate immunity, it is possible that TLR4 may also participate in soluble UA uptake and play a role in soluble UA-induced renal injury. Therefore, in the present study, we used $1 \mu \mathrm{M}$ of the TLR4 inhibitor, TAK242, which has been shown to fully block TLR4 signaling, in order to examine the specific effects of TLR4. TAK242 reversed the NALP3 activation and caspase-1 overexpression induced by soluble UA, suggesting the full dependence of NALP3 and caspase-1 activation on TLR4 following stimulation with soluble UA. These findings support our hypothesis that TLR4 mediates soluble UA uptake and initiates the downstream injury induced by soluble UA.

Nevertheless, unlike the complete blockade of the NALP3 inflammasome and caspase- 1 by TAK 242 , TAK 242 only partially inhibited the upregulation of IL-1 $\beta$ following incubation with soluble UA. It has been reported that apart from the classical cleavage pattern for IL- $1 \beta$ by caspase- 1 , IL- $1 \beta$ can also be cleaved from pro-IL-1 $\beta$ by protease (48) which has been detected in both the proximal and distal renal tubules in normal renal tissue, as well as in patients with tubular disorders (49). Alternatively, cathepsin D has also been suggested as another possible means of IL- $1 \beta$ processing, as shown in the acidosis driven damage-associated molecular patterns (DAMPs) in cultured primary mouse glial cells (50). It is possible that there are other pathways available for IL-1 $\beta$ processing during soluble UA-induced tubular injury and the urate transporter may play a role; however, this requires further investigation.

In conclusion, our present findings suggest that soluble UA induces the formation of the NALP3 inflammasome, caspase- 1 activation, IL-1 $\beta$ expression and ICAM-1 synthesis in human primary renal PTECs through a TLR4-dependent pathway, leading to the activation of innate immunity and the induction of pro-inflammatory cytokine production in human primary renal PTECs, as illustrated in Fig. 5. However, further studies on soluble UA using animal models and renal biopsy samples from patients with hyperuricemia are warranted to verify these findings in vivo.

\section{Acknowledgements}

The results of the present study have been presented in the form of a poster at the World Congress of Nephrology 2013 (May 31 to June 4, Hong Kong). The present study was financially suported by the National Natural Science Foundation of China (grant no. 30900684/C140405) and the Shanghai Medical Guide of Science and Technology Projects (grant no. 114119a6200).

\section{References}

1. Macisaac RJ, Ekinci EI and Jerums G: Markers of and risk factors for the development and progression of diabetic kidney disease. Am J Kidney Dis 63 (Suppl 2): S39-S62, 2014.
2. Rizzo M, Obradovic M, Labudovic-Borovic M, et al: Uric acid metabolism in pre-hypertension and the metabolic syndrome. Curr Vasc Pharmacol 12: 572-585, 2014.

3. Johnson RJ, Nakagawa T, Sanchez-Lozada LG, Shafiu M, Sundaram S, Le M, Ishimoto T, Sautin YY and Lanaspa MA: Sugar, uric acid, and the etiology of diabetes and obesity. Diabetes 62: 3307-3315, 2013.

4. Zhou Y, Fang L, Jiang L, Wen P, Cao H, He W, Dai C and Yang J: Uric acid induces renal inflammation via activating tubular NF- $\kappa \mathrm{B}$ signaling pathway. PLoS One 7: e39738, 2012.

5. Kang DH, Nakagawa T, Feng L, Watanabe S, Han L, Mazzali M, Truong L, Harris R and Johnson RJ: A role for uric acid in the progression of renal disease. J Am Soc Nephrol 13: 2888-2897, 2002.

6. Liu-Bryan R, Scott P, Sydlaske A, Rose DM and Terkeltaub R: Innate immunity conferred by Toll-like receptors 2 and 4 and myeloid differentiation factor 88 expression is pivotal to monosodium urate monohydrate crystal-induced inflammation. Arthritis Rheum 52: 2936-2946, 2005.

7. Rock KL, Kataoka H and Lai JJ: Uric acid as a danger signal in gout and its comorbidities. Nat Rev Rheumatol 9: 13-23, 2013.

8. Ghaemi-Oskouie F and Shi Y: The role of uric acid as an endogenous danger signal in immunity and inflammation. Curr Rheumatol Rep 13: 160-166, 2011.

9. Grainger R, McLaughlin RJ, Harrison AA and Harper JL: Hyperuricaemia elevates circulating CCL2 levels and primes monocyte trafficking in subjects with inter-critical gout. Rheumatology (Oxford) 52: 1018-1021, 2013.

10. Pineda C, Amezcua-Guerra LM, Solano C, RodriguezHenríquez P, Hernández-Díaz C, Vargas A, Hofmann F and Gutiérrez M: Joint and tendon subclinical involvement suggestive of gouty arthritis in asymptomatic hyperuricemia: an ultrasound controlled study. Arthritis Res Ther 13: R4, 2011.

11. Kanellis J, Watanabe $\mathrm{S}$, Li JH, et al: Uric acid stimulates monocyte chemoattractant protein-1 production in vascular smooth muscle cells via mitogen-activated protein kinase and cyclooxygenase-2. Hypertension 41: 1287-1293, 2003.

12. Kang DH, Park SK, Lee IK and Johnson RJ: Uric acid-induced C-reactive protein expression: implication on cell proliferation and nitric oxide production of human vascular cells. J Am Soc Nephrol 16: 3553-3562, 2005

13. Sánchez-Lozada LG, Lanaspa MA, Cristóbal-García M, GarcíaArroyo F, Soto V, Cruz-Robles D, Nakagawa T, Yu MA, Kang DH and Johnson RJ: Uric acid-induced endothelial dysfunction is associated with mitochondrial alterations and decreased intracellular ATP concentrations. Nephron Exp Nephrol 121: e71-e78, 2012.

14. Sautin YY, Nakagawa T, Zharikov S and Johnson RJ: Adverse effects of the classic antioxidant uric acid in adipocytes: NADPH oxidase-mediated oxidative/nitrosative stress. Am J Physiol Cell Physiol 293: C584-C596, 2007.

15. Albertoni G, Maquigussa E, Pessoa E, Barreto JA, Borges F and Schor N: Soluble uric acid increases intracellular calcium through an angiotensin II-dependent mechanism in immortalized human mesangial cells. Exp Biol Med (Maywood) 235: 825-832, 2010.

16. Convento MS, Pessoa E, Dalboni MA, Borges FT and Schor N: Pro-inflammatory and oxidative effects of noncrystalline uric acid in human mesangial cells: contribution to hyperuricemic glomerular damage. Urol Res 39: 21-27, 2011.

17. Borges FT, Dalboni MA, Michelacci YM and Schor N: Noncrystalline uric acid inhibits proteoglycan and glycosaminoglycan synthesis in distal tubular epithelial cells (MDCK). Braz J Med Biol Res 43: 957-963, 2010.

18. Mazzali M, Hughes J, Kim YG, Jefferson JA, Kang DH, Gordon KL, Lan HY, Kivlighn S and Johnson RJ: Elevated uric acid increases blood pressure in the rat by a novel crystalindependent mechanism. Hypertension 38: 1101-1106, 2001.

19. Ficociello LH, Rosolowsky ET, Niewczas MA, et al: Highnormal serum uric acid increases risk of early progressive renal function loss in type 1 diabetes: results of a 6-year follow-up. Diabetes Care 33: 1337-1343, 2010.

20. Imig JD and Ryan MJ: Immune and inflammatory role in renal disease. Compr Physiol 3: 957-976, 2013.

21. Webb R, Jeffries M and Sawalha AH: Uric acid directly promotes human T-cell activation. Am J Med Sci 337: 23-27, 2009.

22. Shi Y, Mucsi AD and Ng G: Monosodium urate crystals in inflammation and immunity. Immunol Rev 233: 203-217, 2010.

23. Kanneganti TD, Ozören N, Body-Malapel M, et al: Bacterial RNA and small antiviral compounds activate caspase-1 through cryopyrin/Nalp3. Nature 440: 233-236, 2006. 
24. Brough D and Rothwell NJ: Caspase-1-dependent processing of pro-interleukin-1beta is cytosolic and precedes cell death. J Cell Sci 120: 772-781, 2007.

25. Witkowska AM and Borawska MH: Soluble intercellular adhesion molecule-1 (sICAM-1): an overview. Eur Cytokine Netw 15: 91-98, 2004

26. Johnson RJ, Nakagawa T, Jalal D, Sánchez-Lozada LG, Kang DH and Ritz E: Uric acid and chronic kidney disease: which is chasing which. Nephrol Dial Transplant 28: 2221-2228, 2013.

27. Ryu ES, Kim MJ, Shin HS, Jang YH, Choi HS, Jo I, Johnson RJ and Kang DH: Uric acid-induced phenotypic transition of renal tubular cells as a novel mechanism of chronic kidney disease. Am J Physiol Renal Physiol 304: F471-F480, 2013.

28. Yang Z, Xiaohua W, Lei J, Ruoyun T, Mingxia X, Weichun H, Li F, Ping W and Junwei Y: Uric acid increases fibronectin synthesis through upregulation of lysyl oxidase expression in rat renal tubular epithelial cells. Am J Physiol Renal Physiol 299: F336-F346, 2010.

29. Quan H, Peng X, Liu S, Bo F, Yang L, Huang Z, Li H, Chen X and Di W: Differentially expressed protein profile of renal tubule cell stimulated by elevated uric acid using SILAC coupled to LC-MS. Cell Physiol Biochem 27: 91-98, 2011.

30. Han HJ, Lim MJ, Lee YJ, Lee JH, Yang IS and Taub M: Uric acid inhibits renal proximal tubule cell proliferation via at least two signaling pathways involving PKC, MAPK, cPLA2, and NF-kappaB. Am J Physiol Renal Physiol 292: F373-F381, 2007.

31. Chen W, Roncal-Jimenez C, Lanaspa M, Gerard S, Chonchol M, Johnson RJ and Jalal D: Uric acid suppresses 1 alpha hydroxylase in vitro and in vivo. Metabolism 63: 150-160, 2014.

32. Hua S: Targeting sites of inflammation: Intercellular adhesion molecule-1 as a target for novel inflammatory therapies. Front Pharmacol 4: 127, 2013.

33. Schiffrin EL: The immune system: role in hypertension. Can J Cardiol 29: 543-548, 2013.

34. Schiffrin EL: Immune mechanisms in hypertension and vascular injury. Clin Sci (Lond) 126: 267-274, 2014

35. Tsuboi N, Yoshikai Y, Matsuo S, Kikuchi T, Iwami K, Nagai Y, Takeuchi O, Akira S and Matsuguchi T: Roles of toll-like receptors in $\mathrm{C}-\mathrm{C}$ chemokine production by renal tubular epithelial cells. J Immunol 169: 2026-2033, 2002.

36. Hato T, El-Achkar TM and Dagher PC: Sisters in arms: myeloid and tubular epithelial cells shape renal innate immunity. Am J Physiol Renal Physiol 304: F1243-F1251, 2013.

37. Newton K and Dixit VM: Signaling in innate immunity and inflammation. Cold Spring Harb Perspect Biol 4: 4, 2012.

38. Sloane JA, Blitz D, Margolin Z and Vartanian T: A clear and present danger: endogenous ligands of Toll-like receptors. Neuromolecular Med 12: 149-163, 2010.
39. Cha JJ, Hyun YY, Lee MH, et al: Renal protective effects of toll-like receptor 4 signaling blockade in type 2 diabetic mice. Endocrinology 154: 2144-2155, 2013.

40. Lee IT, Shih RH, Lin CC, Chen JT and Yang CM: Role of TLR4/ NADPH oxidase/ROS-activated p38 MAPK in VCAM-1 expression induced by lipopolysaccharide in human renal mesangial cells. Cell Commun Signal 10: 33, 2012.

41. Lin M, Yiu WH, Wu HJ, Chan LY, Leung JC, Au WS, Chan KW, Lai KN and Tang SC: Toll-like receptor 4 promotes tubular inflammation in diabetic nephropathy. J Am Soc Nephrol 23: 86-102, 2012.

42. Cheng A, Dong Y, Zhu F, Liu Y, Hou FF and Nie J: AGE-LDL activates Toll like receptor 4 pathway and promotes inflammatory cytokines production in renal tubular epithelial cells. Int J Biol Sci 9: 94-107, 2013

43. Qing YF, Zhang QB, Zhou JG and Jiang L: Changes in toll-like receptor (TLR) 4-NFאB-IL1 $\beta$ signaling in male gout patients might be involved in the pathogenesis of primary gouty arthritis. Rheumatol Int 34: 213-220, 2014.

44. Correa-Costa M, Braga TT, Semedo P, et al: Pivotal role of Toll-like receptors 2 and 4, its adaptor molecule MyD88, and inflammasome complex in experimental tubule-interstitial nephritis. PLoS One 6: e29004, 2011.

45. Bergler T, Hoffmann U, Bergler E, Jung B, Banas MC, Reinhold SW, Krämer BK and Banas B: Toll-like receptor 4 in experimental kidney transplantation: early mediator of endogenous danger signals. Nephron Exp Nephrol 121: e59-e70, 2012.

46. Anzai $\mathrm{N}$ and Endou $\mathrm{H}$ : Urate transporters: an evolving field. Semin Nephrol 31: 400-409, 2011.

47. Cronstein BN and Terkeltaub R: The inflammatory process of gout and its treatment. Arthritis Res Ther 8 (Suppl 1): S3, 2006.

48. van de Veerdonk FL and Netea MG: New insights in the immunobiology of IL-1 family members. Front Immunol 4: 167, 2013.

49. Manea M, Tati R, Karlsson J, Békássy ZD and Karpman D: Biologically active ADAMTS13 is expressed in renal tubular epithelial cells. Pediatr Nephrol 25: 87-96, 2010.

50. Edye ME, Lopez-Castejon G, Allan SM and Brough D: Acidosis drives damage-associated molecular pattern (DAMP)-induced interleukin-1 secretion via a caspase-1-independent pathway. J Biol Chem 288: 30485-30494, 2013

51. Chen Z, Liu Y, Sun B, et al: Polyhydroxylated metallofullerenols stimulate IL-1beta secretion of macrophage through TLRs/ MyD88/NF- $\kappa \mathrm{B}$ pathway and $\mathrm{NLRP}_{3}$ inflammasome activation. Small 10: 2362-2372, 2014

52. Palová-Jelínková L, Dáňová $\mathrm{K}$, Drašarová $\mathrm{H}$, et al: Pepsin digest of wheat gliadin fraction increases production of IL-1 $\beta$ via TLR4/MyD88/TRIF/MAPK/NF- $\kappa$ B signaling pathway and an NLRP3 inflammasome activation. PloS One 8: e62426, 2013. 